\title{
Intergenerational Knowledge Sharing in Business Settings A Comparative Case Study between Germany and South-Korea
}

\author{
Lea Wöbbekind \\ University of Hildesheim, Germany \\ woebbek@uni-hildesheim.de \\ Christa Womser-Hacker \\ University of Hildesheim, Germany \\ womser@uni-hildesheim.de \\ Dowan Kim \\ Pai Chai University, South Korea \\ dwkim@pcu.ac.kr
}

\begin{abstract}
Summary
Researchers view knowledge as an essential organizational asset for corporate success. Over the past decades, many studies explored the management of knowledge in multinational companies. Nowadays in the context of demographic change, intergenerational aspects and age have become crucial factors for knowledge sharing. However, it remains unclear how cultural attitudes affect knowledge sharing within companies. The purpose of this paper is to give new insights into the impact of culture and age on knowledge sharing in German and South-Korean companies. To understand how culture influences an individuals' perception of age and generation in the context of knowledge sharing in an organization, a qualitative approach including semi-structured interviews is chosen.
\end{abstract}

Key words: knowledge management, intergenerational knowledge sharing, demographic change, cultural aspects

\section{Introduction}

Nowadays, many companies face relevant changes within their economic environment and regarding their future. At the organizational level, knowledge becomes an important asset. Moreover, knowledge sharing is seen as a strategic advantage of companies for success and competition (Nonaka, Takeuchi, 1995; Hwang et al., 2015). Workforces are becoming older and more age-diverse. It is necessary for organizations to avoid the loss of knowledge through the retirement of older employees. However, this is not an easy task due to the intangible character of knowledge. Individual and organizational knowledge differ in several characteristics as well as different distribution mechanisms. As several studies point out, culture, embodied in language, rules or concepts, affects the knowledge sharing of individuals and groups (DeLong, Fahey, 2000; Ardichvili et al., 2006). Thomas and Utler (2013: 41) define culture as a universal orientation system for societies or groups. This system influences the perception, thinking and norms and defines an individual's membership of the society. Moreover, many studies in the research area of knowledge management and knowledge sharing focus on the effects of cultural diversity in multinational companies on communication and knowledge transfer (Wikström et al., 2018).

\section{Purpose}

An overall aim of this article is to explore cultural issues on knowledge sharing in national companies. Besides individual, social and organizational approaches on intergenerational knowledge sharing (Wíden, 2017) more research needs to be done to explore the impact of culture on intergenerational knowledge sharing. The basis for this study is the KNOWISH project (Knowledge sharing between age groups) and previous master theses from Brinken and Kock (2017) as well as Ivantsova and Sivén (2016). Both theses explore knowledge sharing in German and Finnish companies. Semi-structured interviews with employees of different age groups were conducted. Using this knowledge this case study aims to: 
- Provide an in-depth understanding of what generational effects and cultural issues appear in a South-Korean research institute.

- Compose this knowledge and compare the results with the two German case studies to understand the impact of culture on intergenerational knowledge sharing in different companies.

\section{Generation model in South Korea}

Kuyken (2012) portraits the generation model of baby boomers, generation X, and generation $\mathrm{Y}$ in the context of knowledge sharing in an organization (Zemke et al., 2000; DeLong, 2004). For the new case study, it is important to adapt the generation model to South-Korean culture.

Park and Park (2018) use the mentioned model above and add South-Korean characteristics for each particular generation and also focus on the effects on workplaces. They present a unique generation, called generation 386, which can be only found in South-Korea. Members of generation 386 are born between 1960 to 1969. The term was introduced in the 1990s to describe people in their 30s who attended universities in the 80s. The group of generation 386 witnessed a military dictatorship and therefore stands up for democratization in Korea. Moreover, they experienced the economic recession and the Asian financial crisis that continued in 1997 (Park, 2007). They appreciate traditional values and collectivism. Nowadays, individuals of this generation work as heads of departments or directors, generally higher positions in society. Consequently, this generation is responsible for the education of future leaders. It is important to understand the generation 386, as they have a large responsibility in the South-Korean society (Park, Park, 2018). Individuals born between 1970 and 1980 are called Generation X or Shinsedae in South-Korea and refers to the term new generation. Individuals of this group were raised in a better economic situation than the previous generation and experienced more freedom and individualism. They agree that work and career belong to themselves rather than their employers. Moreover, members of this cohort are supposed to be treated individually and focus on work-life balance (Park and Park, 2018). The third generation is called Millennials and refers to generation Y. It comprises of individuals born between 1980 and 1994. This generation was raised among information technologies and is, therefore, more skilled in the use of digital technologies, media and instant communication (Park, Park, 2018). In contrast to generation 386, this group is supposed to be freer from political or ideological tendencies (Park, 2007). Members of generation Y value personal life more than individuals from older generations. Another interesting generational aspect occurs in the context of over-parenting. It signifies that members of generation $\mathrm{Y}$ are used to receive solutions and caring from their parents. They may fail to develop their own identity and adequate independence until reaching adulthood. As a consequence, the hierarchical structures and values that older generations have in South- Korea are not likely to promote the strengths of generation Y at work (Park, Park, 2018). Because of rapid social transformation during only a few decades, South-Korean society seems to experience wider gaps between older and younger generations.

Several studies explore the organizational impact of added values for mixed-age teams. Bratianu and Leon (2015) emphasize the positive effects regarding the sharing of deep knowledge of more experienced employees, including know-how, working morale and quality, while younger employees include broad knowledge, regarding a high ability to learn. In theory, it encourages mutual learning and stimulates knowledge increasing. For our study, based on the year of birth, we recruited two participants from generation 386, four participants from generation $\mathrm{X}$ and five employees from generation $\mathrm{Y}$ in the South-Korean research institute.

\section{Research method}

In order to answer the research questions, an interdisciplinary approach from an information science perspective is chosen. We employed an empirical qualitative research model, as it allows for exploring unknown phenomena (Rosenthal, 2008: 18). In contrast to quantitative methods, this enables an in-depth examination of attitudes and values, as this study is not intended to test hypotheses nor statistical analysis (Raithel, 2006: 8). Eleven interviews were conducted with SouthKorean employees in a business setting. The interview guideline from Brinken and Kock (2017: 175 ff.) is re-used. It includes 30 questions in 5 categories about communication, knowledge and learning aspects, organizational learning, systems, and virtual communities. The selection of young and old 
interviewees was not random, as the age of interviewees is between 26 and 54 . The qualitative approach employed interviews from 30 to 60 minutes. Table 1 shows the demographic data of participants. In general, semi-structured interviews contain open-ended questions and were significantly useful for our approach. Other questions that arise during the interview can be addressed and discussed. Individual in-depth interviews can dip deep into the past of the interviewee and examine social and personal matters.

Table 1. Demographic data of the South-Korean participants

\begin{tabular}{|c|c|c|c|c|}
\hline Number & Gender & Job description & $\begin{array}{c}\text { Time in the } \\
\text { company }\end{array}$ & $\begin{array}{c}\text { Year of } \\
\text { birth }\end{array}$ \\
\hline 1 & $\mathrm{~m}$ & Senior researcher & 5 years & 1975 \\
\hline 2 & $\mathrm{~m}$ & Senior researcher & 4 years & 1976 \\
\hline 3 & $\mathrm{~m}$ & Ph.D. student & 4 years & 1992 \\
\hline 4 & $\mathrm{~m}$ & Ph.D. student & 3 years & 1986 \\
\hline 5 & $\mathrm{~m}$ & Senior researcher & 2 years & 1977 \\
\hline 6 & $\mathrm{~m}$ & Senior researcher & 12 years & 1981 \\
\hline 7 & $\mathrm{~m}$ & Senior researcher & 4 years & 1983 \\
\hline 8 & $\mathrm{~m}$ & Professor, Head of Lab & 8 years & 1972 \\
\hline 9 & $\mathrm{f}$ & Ph.D. student & 1.5 years & 1980 \\
\hline 10 & $\mathrm{~m}$ & Team manager & 22 years & 1965 \\
\hline 11 & $\mathrm{~m}$ & Department leader & 28 years & 1965 \\
\hline
\end{tabular}

The German case studies (Brinken, Kock, 2017) include one middle-sized and one small business company: An Optician store and software development company. The interviewees $(m=7, f=3)$ from the first company include one trainee (born 1994), three opticians (born 1992, 1994 and 1992), three shop managers (born 1955, 1976 and 1953), one optometrist (born 1984) and two employees from the upper management (born 1964 and 1952). The demographic data revealed a particularly broad age range from 22 to 64 years. The software and IT company is relatively young with only a few older employees: Three software developer (born 1981, 1986 and 1974), one student employee (born 1995), one team leader (born 1982), two project managers (born 1965 and 1980), two consultants (born 1969 and 1986) and one executive board member (born 1952). There were nine males and one female interview participants. The qualitative data analysis involved several research steps. To get an overview of the rich data, several reading sessions were conducted to explore initial ideas and interesting, related empirical data characteristics. Potential patterns were gathered and categorized for interpretation. After the data analysis follows the interpretation of surveyed data. Passages are formed into paragraphs of the interviews that are grouped based on their similarity (Mayring, 2015: 18).

\section{Challenges}

A literature review shows that more empirical research needs to be done to explore the advantages and disadvantages of conducting qualitative research, like interviews, in South-Korea. Park and Lunt (2015) conducted a qualitative study with Korean participants in the public sector to examine practical issues between Anglophone techniques and countries with a Confucian background. The authors highlight different issues between Anglophone research techniques, like interviews, with SouthKorean participants. The main difficulties occurred with problems of the comprehensibility of the research question and trust issues between the interviewees and interviewer. Participants expressed difficulties in answering open questions and expressing their individual opinion. Attention must be paid to the impact of indirectness. Indirectness is a communication skill that expresses politeness or self-protection and is typically used in Asian countries. It is also utilized to avoid embarrassment or misunderstandings. The main impact on the interview may be that participants use proper words or behaviors instead of expressing honest statements or opinions (Zhang, You, 2009). As the Confucian background approves hierarchy and social mores in South-Korea, the researchers were worried that social networks of the participant's influence on the recruitment process (Park, Lunt, 2015). This may result in a too homogeneous group of interviewees. These insights were consulted to understand the limitations of Western research methods in an Asian setting. The framework was taken into account to deal with arising problems during the interviews, as the interviewer had a non-Korean background. 


\section{Results}

To present the findings a qualitative approach with semi-structured interviews is conducted with South-Korean employees to explore the impact of culture on intergenerational knowledge sharing. Quotes from the interviews will be shown to explain the findings. The data revealed insights into age structures, influence of status and (work) experience as well as competencies of each cohort in the organization. The most interesting outcome shows that sharing know-how and expertise between different age groups is not an important issue in the context of knowledge management and demographic changes. In greater detail, maintaining an orderly and harmonious society, based on Confucian philosophy, is highly relevant at the workplace and forms the relationship of generations in the South-Korean institute: Yes, in that culture because younger people are just educated to obey to older people first. So not asking something. [...] compared to US or Deutschland, in classroom we usually do not ask something. Just listen the teacher's message and classes and memorize something. That is our culture. That is an obstacle in knowledge sharing. [...] (P5, Generation X).

The appreciation of seniority is integrated into a three-stage age system: The classification of young, old and elder employees in the organization. This hierarchical system is based on chronological and professional age, status and position in the institute and shows the impact of hierarchy on work life. The study also revealed interesting insights into the characteristics of each generation, which support the theoretical framework of generations by Kuyken (2012) and Park and Park (2018). Younger employees with less status and experience are excluded from decision-making processes in departments, with the following explanation: Because older researchers have the more experience. Usually, in realistic case, the solution is focused on the experience ( $\mathrm{P} 7$, Generation $\mathrm{X})$.

Younger employees demonstrate advanced competencies in technology and self-studying to gain knowledge. Regarding knowledge sharing, they emphasize learning especially from older and elder employees. Older employees are characterized as knowledge carriers, especially for knowledge about the company. Their professional age signifies high social competence. Based on the competencies and inabilities of young and older employees, a teacher-student relationship between these generations at the workplace could be revealed. The third identified group in the organization are elder employees. From the age of 50 up, they have leading positions in the departments. They, as several participants explained, have a higher status in society than younger employees that include qualified communication skills and experience. In comparison to generation $\mathrm{Y}$, they lack openness for innovation and new technologies. As teams are organized with employees of different generations, the influence of hierarchy is shown by more responsibilities of a member of generation $\mathrm{X}$ and generation 386. Remarkably, younger employees mention an important communication style when working or communicating with elder employees: Showing respect, manners and the use of polite language. Moreover, respect is shown in general agreement with work decisions that might lead to communication and generation issues: Korean society community they have a hierarchy structure. Many younger people bad situation. Sometime older people supervise provide. So, we can feel difficult communication with the supervisor (P11, Generation 386).

Therefore, the data analysis revealed a business structure of top-down communication as well as a hierarchical structure in the organization that is identified by members of different generations. Apart from generational aspects, knowledge retention is not related to the success and competition of the company. Besides the findings of generational factors and barriers for intergenerational knowledge sharing, knowledge hoarding might be an important issue. As already mentioned, each generation acquired specific expertise and skills in different work areas. Interestingly, the analysis revealed that sharing expertise is not correlated with benefits and advantages for the management and individual employees. Reasons for this outcome include the lack of good quality of knowledge, human factors and trust: To get the other people's experience, some knowledge, it is very difficult. We are not a machine, we are human. It is difficult to communicate with unknown people ( $\mathrm{P} 1$, Generation $\mathrm{X})$. A younger employee describes communication issues with elder colleagues in greater detail: So that is the reason why I told you the communication is usually top-down. But that is very, how can I say... it is very... it seems like to slow. They are very far, it is very hard to communicate with them directly (P3, Generation Y).

The interviewee's statements support the result that no official channels or guidelines for sharing knowledge are foreseen. Therefore, no intrinsic or extrinsic motivational factors for knowledge sharing in the organization could be revealed. 
The impact of culture and intergenerational aspects in the German case studies (Brinken, Kock, 2017) lay on young employees being better in handling technologies. They are open-minded towards new trends or trying new things out. This relates to the flexibility and motivation of young employees.

The competencies of older employees lay in their work experience and proficiency in communication skills and less in learning and using new systems. The competencies both of young and old employees demonstrate that knowledge sharing happens mutually, based on skills. Both groups can learn from each other and are willing to share their best practices or expertise. More similarities can be found by an open atmosphere in both companies, the prioritization of teamwork and a flat hierarchy structure.

\section{Comparison of knowledge sharing and generational aspects}

The analysis of generational aspects in Germany and South-Korea revealed two different concepts of age: The German interviewees describe a non-hierarchical system of young and old employees. Both groups are supposed to be knowledge carriers. Therefore, knowledge sharing happens mutually between them at the workplace. Generally, German employees show an open-minded, critical thinking and rational attitude towards knowledge sharing.

According to the conducted interviews, knowledge sharing happens mutually in the German case studies (Brinken, Kock, 2017). Especially tacit knowledge is identified as an important asset for sharing with colleagues. Helping each other at work is natural and happens on a daily basis. Moreover, the atmosphere has a very positive impact on communication and knowledge sharing. As already mentioned, the German interviewees describe a knowledge sharing-friendly environment characterized by a familiar atmosphere, team spirit and strong relationships between all employees. In both German companies, this atmosphere is created by the appreciation of open communication as a corporate value and community-building events. Team spirit is also reflected in the way employees learn within the organization. The German interviewees mention that they learn by reflecting past situations together with colleagues, by exchanging experiences in training and meetings and by observing colleagues. This behavior demonstrates flat hierarchical structures in the German companies and openness for direct communication and discussions of experienced and inexperienced employees. Nevertheless, this structure is not necessarily associated with culture. The generation model, introduced by Kuyken (2012) and Park and Park (2018), is characterized by shared values and characteristics of individuals based on its socialization. However, these results differ greatly from those in the South-Korean organization. Table 2 shows the outcomes of both studies in greater detail.

Table 2. Comparison of the results

\begin{tabular}{|l|l|l|}
\hline \multicolumn{1}{|c|}{ Feature } & \multicolumn{1}{c|}{ South-Korea } & \multicolumn{1}{c|}{ Germany } \\
\hline Age structure & 3-stage age model & 2-stage age model \\
\hline Hierarchy & Particularly pronounced in the company & Non-existent in the companies \\
\hline Communication style & $\begin{array}{l}\text { Formal and respectful language style, top- } \\
\text { down communication }\end{array}$ & Direct and open, feedback culture \\
\hline Working environment & Self-studying & Teamwork, helping each other \\
\hline Individual motivation & No intrinsic motivation could be identified & $\begin{array}{l}\text { Intrinsic motivation (responsibility } \\
\text { and joy) }\end{array}$ \\
\hline Experience & $\begin{array}{l}\text { Age and status in the company form } \\
\text { experience }\end{array}$ & Professional age (work experience) \\
\hline Technologies & Use of virtual communities & Intranet, social networks \\
\hline Understanding of generations & Teacher-student relationship & Equal relationship, knowledge carriers \\
\hline Support by the management & No official support & To some degree \\
\hline Knowledge loss & $\begin{array}{l}\text { Knowledge hoarding, required knowledge is } \\
\text { gained by experience }\end{array}$ & Less knowledge hoarding \\
\hline
\end{tabular}

Social and cultural differences between younger and elder employees (for example shown in communication styles and the general understanding of generations) explain the mentioned generation gap in the South-Korean workplace. For example, old and elder employees are responsible for decision-making. Members with a lower chronological age are excluded from management decisions. To balance this gap, younger employees are very well in self-learning and studying. Therefore, in both cases, a broad range of expertise and know-how can be identified. 


\section{The impact of culture on intergenerational knowledge and knowledge sharing}

Teams of mixed ages provide diverse knowledge and expertise. Transferring knowledge in intergenerational teams or departments can overcome the knowledge gaps of individuals. In the South-Korean company, older and elder employees are less innovative and open to changes and lack the motivation to learn new skills. This knowledge gap is compensated by the advanced skills of younger colleagues regarding information technology. A broad range of ages shows a high diversity of skills, capabilities, and strengths for each cohort. Each generation contains knowledge carriers and expertise. Especially South-Korean culture revealed its influence on intergenerational knowledge sharing. Its impact is shown in the behaviors and values of individuals. In detail, the influence of cultural aspects is demonstrated by hierarchy and high appreciation for seniority.

Many barriers to knowledge sharing could be revealed in both studies. Reasons for hoarding knowledge include trust issues, limited support by the management, hierarchy structures and lack of good quality knowledge. Nonetheless, knowledge sharing is mainly a process in one direction only within the South-Korean organization and is characterized by hierarchy and a top-down communication style. Whenever expertise is shared, it is often limited to a small team or single colleagues and does not affect the entire organization or a larger team. Interestingly, teamwork is considered to be less important in the organization. Based on the theoretical background, Confucian philosophy has an important role. It shapes the relationship between young, old and elder employees. Intergenerational knowledge sharing is negatively influenced by formal language styles. Younger and also older generations behave politely and considerately towards individuals with a higher status and elderly. South-Korea is an example of a country with pronounced collectivism and strong hierarchies. Additionally, there is no official support or system to share or gain knowledge in the company. The phenomena of knowledge barriers revealed that knowledge hoarding, as well as knowledge loss as a result of the retirement of elder employees, is a possible scenario.

\section{Conclusion}

The companies differ largely because of domains, working environment, age structures and work routine. Nevertheless, interesting insights into the impact of culture on intergenerational knowledge is illustrated. The presence of some aspects of social norms, values, and behaviors leads to the assumption they might be important to intergenerational knowledge sharing. Based on these concepts, intergenerational knowledge sharing is not actively pursued or encouraged within the South- Korean company. On the contrary, the German case studies show how working environments and intrinsic motivation of individuals favorably affect knowledge sharing between employees of different age groups. These differences in the results show that culture in Western and Asian countries shapes assumptions about what knowledge is important and how it will be used and shared within an organization or department.

Several individual and organizational reasons for knowledge hoarding and knowledge loss could be revealed. Age structures, like a three-stage age model in South Korea, demonstrate the influence of culture.

\section{References}

Ardichvili, A., Marer, W., Wei, L., Wentling, T., Stuedemann, R. (2006). Cultural influences on knowledge sharing through online communities of practice. // Journal of Knowledge Management 10, 4, 541-554

Bratianu, C., Leon, R. D. (2015). Strategies to enhance intergenerational learning and reducing knowledge loss. // VINE 45, 4, 551-567

Brinken, H., Kock. H. (2017). Exploring intergenerational Knowledge sharing in Organizations. https://edoc.huberlin.de/handle/18452/20725 (2019/08/01)

DeLong, D., Fahey, L. (2000). Diagnosing cultural barriers to knowledge management. // Academy of Management Executive 14, 4, 113-127

DeLong, D. (2014). Lost knowledge. Confronting the threat of an aging workforce. Oxford: University Press

Hwang, E. H., Singh, P. V., Argote, L. (2015). Knowledge sharing in online communities: Learning to cross geographic and hierarchical boundaries. // Institute for Operations Research and the Management Sciences 1, 2, 1593-1611

Ivantsova, E., Sivén, T. (2016). Intergenerational knowledge sharing within two case studies. http://www.doria.fi/bitstream/handle/10024/131066/Intergenerational\%20knowledge\%20sharing\%20within\%20two\%20 case\%20studies.\%202017.pdf?sequence=1\&isAllowed=y $(2019 / 08 / 02)$

Kuyken, K. (2012). Knowledge communities: towards a re-thinking of intergenerational knowledge transfer. // Journal of information and knowledge management systems 42, 3/4, 366-381

Mayring, P. (2015). Qualitative Inhaltsanalyse. Grundlagen und Techniken. Weinheim/Basel: Beltz Verlag 
Nonaka, I., Takeuchi, H. (1995). The Knowledge-Creating Company: How Japanese Companies Create the Dynamics of Innovation. New York: Oxford University Press

Park, S., Lunt, N. (2015). Confucianism and qualitative interviewing. Working Seoul to soul. // Forum Qualitative Sozialforschung 16,2

Park, S., Park, S. (2018). Exploring the generation gap in the workplace in South Korea. // Human Resource Development International 21, 3, 276-283

Park, S. Y. (2007). Shinsedae: Conservative attitudes of a new generation in South Korea and the impact on the Korean presidential election. // EWC Insights 2, 1, 1-4

Raithel, J. (2006). Quantitative Forschung. Ein Praxisbuch. Wiesbaden: VS Verlag für Sozialwissenschaften

Rosenthal, G. (2008). Interpretative Sozialforschung: Eine Einführung. Weinheim/München: Juventa-Verlag

Thomas, A., Utler, A. (2013). Kultur, Kulturdimensionen und Kulturstandards. In: Genkova, P.; Ringeisen, T.; Leong F. Handbuch Stress und Kultur. Wiesbaden: Springer

Wíden, G. (2017). Individual, social and cultural approaches to knowledge sharing. // Journal of Information Science Theory and Practice 5, 3, 6-14

Wikström, E., Eriksson, E., Karamehmedovic, L., Liff, R. (2018) Knowledge retention and age management - senior employees' experiences in a Swedish multinational company. // Journal of Knowledge Management 22, 7, 1510-1526

Zemke, R., Rains, C., Filipczak, B. (2000). Generations at work. New York: American Management Association

Zhang, F., You, H. (2009). Motives of indirectness in daily communication. An Asian Perspective. // CCSE Journal 1, 2, 99 102 